\title{
Quinoline and Quinazoline Alkaloids against COVID-19: An In Silico Multitarget Approach
}

\author{
Esraa M. O. A. Ismail, ${ }^{1}$ Shaza W. Shantier ${ }^{1},{ }^{1}$ Mona S. Mohammed, ${ }^{2}$ Hassan H. Musa, ${ }^{3}$ \\ Wadah Osman, ${ }^{2}$ and Ramzi A. Mothana ${ }^{4}$ \\ ${ }^{1}$ Department of Pharmaceutical Chemistry, Faculty of Pharmacy, University of Khartoum, Khartoum, P.O. Box 1996, Sudan \\ ${ }^{2}$ Department of Pharmacognosy, Faculty of Pharmacy, University of Khartoum, Khartoum, P.O. Box 1996, Sudan \\ ${ }^{3}$ Faculty of Medical Laboratory Sciences, University of Khartoum, Khartoum, Sudan \\ ${ }^{4}$ Department of Pharmacognosy, College of Pharmacy, King Saud University, Riyadh, Saudi Arabia
}

Correspondence should be addressed to Shaza W. Shantier; sshantier@yahoo.com

Received 4 August 2020; Revised 5 November 2020; Accepted 13 March 2021; Published 25 March 2021

Academic Editor: Leena Gupta

Copyright ( 92021 Esraa M. O. A. Ismail et al. This is an open access article distributed under the Creative Commons Attribution License, which permits unrestricted use, distribution, and reproduction in any medium, provided the original work is properly cited.

\begin{abstract}
The recent outbreak of the highly contagious coronavirus disease 2019 (COVID-19) caused by the novel coronavirus SARS-CoV-2 has created a global health crisis with socioeconomic impacts. Although, recently, vaccines have been approved for the prevention of COVID-19, there is still an urgent need for the discovery of more efficacious and safer drugs especially from natural sources. In this study, a number of quinoline and quinazoline alkaloids with antiviral and/or antimalarial activity were virtually screened against three potential targets for the development of drugs against COVID-19. Among seventy-one tested compounds, twentythree were selected for molecular docking based on their pharmacokinetic and toxicity profiles. The results identified a number of potential inhibitors. Three of them, namely, norquinadoline A, deoxytryptoquivaline, and deoxynortryptoquivaline, showed strong binding to the three targets, SARS-CoV-2 main protease, spike glycoprotein, and human angiotensin-converting enzyme 2. These alkaloids therefore have promise for being further investigated as possible multitarget drugs against COVID-19.
\end{abstract}

\section{Introduction}

In December 2019, a global health concern had been raised by the outbreak of coronavirus disease 2019 (COVID-19) which is caused by SARS-CoV-2. It belongs to the singlestranded positive-sense RNA coronavirus family [1]. Its genome consists of different regions including a spike protein $(\mathrm{S})$ gene, an envelope protein (E) gene, a membrane protein $(\mathrm{M})$ gene, and a nucleocapsid protein $(\mathrm{N})$ gene [2]. The sequence of SARS-CoV-2 showed more than 50\% identity to SARS-CoV and MERS-CoV and closer relation to bat-SL-CoVZC45 [3, 4]. SARS-CoV produces several functional proteins while its main protease is emerging as a promising therapeutic target as it is responsible for the processing of translated polyprotein. Thus, inhibition of the main protease was confirmed to affect the viral replication [5]. Its high sequence conservation with SARS-CoV main protease suggests the effectiveness of HIV-1 protease inhibitors such as nelfinavir against it [6]. SARS-CoV-2 shares the mode of transmission with SARS-CoV and MERS-CoV, after which it binds to ACE2 on the surface of host cells via the receptor-binding domain (RBD) in its spike proteins $[7,8]$. Blocking the ACE2 and RBD interaction by antibodies and inhibitors would be an effective way to stop the virus infection [9].

Symptoms of COVID-19 greatly resembled viral pneumonia ranging from mild to more severe eventually ending in several organ malfunction [6]. Discovery of efficacious drugs for this deadly disease could be achieved by one of the three options: testing the existing antiviral drugs which are already used to treat viral infections, secondly, screening of different existing drugs, and finally, discovery of new specific drugs based on the individual coronavirus genome [10]. Chloroquine, HIV protease inhibitors, ACE-2 
inhibitors, and many other drugs were predicted to be COVID-19 drug candidates [11, 12].

Medicinal plants have pulled in noteworthy consideration since they incorporate bioactive components that could be utilized to design medications against a few ailments with insignificant side effects [13]. The medicinal active compounds of plants have been widely used to treat microbial diseases being antifungal [14], antibacterial [15], and antiviral [16]. Quinoline and quinazoline alkaloids are $\mathrm{N}$-based heterocyclic compounds with a wide range of activities, and many of them have been reported to have antiviral effects $[17,18]$. It is therefore imperative to test their effectiveness in COVID-19.

Computational methods are commonly used for structure-based drug discovery (SBDD) and ligand-based drug discovery (LBDD) $[19,20]$. Since they accelerate the lengthy drug discovery and development process, recently, they have been extensively used for lead discovery against COVID-19 by virtually screening compounds with potential biological activity [21-36]. However, few studies were directed towards the discovery of multitarget drugs [37, 38].

The present study computationally assesses the inhibitory effects of selected natural quinoline and quinazoline alkaloids on three potential SARS-CoV-2 drug targets and predicts their pharmacokinetics and toxicities identifying promising multitarget candidates against COVID-19.

\section{Materials and Methods}

2.1. Data Sources. Literature was surveyed for various phytochemicals with known antiviral and/or antimalarial activities. 71 bioactive alkaloids (quinoline and quinazoline) from different natural sources were selected to be investigated for their activity against COVID-19 virus [17, 18].

2.2. Target Selection and Preparation. COVID-19 main protease domain (PDB ID: 6LU7), COVID-19 spike glycoprotein (PDB ID: 6LZG), and human angiotensin-converting enzyme 2 (ACE2; PDB ID: IR42) were selected as the target proteins. Their 3D structures were retrieved from the RCSB PDB (protein data bank) database. Swiss PDB viewer V.4.1.0 software [39] was used for structure optimization, and the active sites were verified from the UniProt databases.

2.3. Ligands' Preparation. The 3D SDF structures of some compounds were downloaded from the PubChem database, and $2 \mathrm{D}$ structures of the rest were illustrated using ChemSketch. The files were then converted into the PDB format with the aid of Open Babel, energy minimized, and converted into the PDBQT format using the graphical user interface version of PyRx virtual screening tool-python prescription 0.8 .

2.4. Compound Screening Using PyRx Program. Virtual screening was performed using PyRx software and Vina wizard as the engine for docking $[40,41]$. The amino acids' residues in the active site of the protein were selected. The results less than $1.0 \AA$ in positional root-mean-square deviation (RMSD) were considered ideal and clustered together for finding the favorable binding. The highest binding energy (most negative) was considered as the ligand with maximum binding affinity.

2.5. In Silico ADME Properties. The pharmacokinetic (ADME) properties of the selected compounds were predicted using the SwissADME web tool (http://www. swissadme.ch/) [42]. The compounds' structure was retrieved from databases using the import tool on the input zone of the SwissADME submission page and converted into the SMILES format, and then calculations were run. In some cases, the structures were converted into the SMILES format using the Online SMILES Translator (available at https:// cactus.nci.nih.gov/translate/).

2.6. In Silico Toxicity Risks' Assessment and Drug Likeliness. OSIRIS Property Explorer open-source program (http:// www.organicchemistry.org/prog/peo/) [43] was used to evaluate the toxicity risks of the compounds retrieved from PubChem.

2.7. Molecular Docking. Molecular docking was performed using AutoDock 4.0 software, based on the Lamarckian genetic algorithm, which combines energy evaluation through grids of affinity potential to find the suitable binding position for a ligand on a given protein [44, 45]. Polar hydrogen atoms were added to the protein targets, and Kollman united atomic charges were computed. The targets' grid map was calculated and set to $60 \times 60 \times 60$ points with the grid spacing of $0.375 \AA$. The grid box was then allocated properly in the target to include the active residue in the center. The genetic algorithm and its run were set to 10 as the docking algorithms were set on default. Results were finally retrieved as binding energies.

2.8. Analysis and Visualization. The resultant docking files with poses showing the lowest binding energies were visualized using DS Visualizer Client (Windows 64 bit) (267 MB).

\section{Results}

3.1. Compounds' Screening. Seventy one natural alkaloids were virtually screened to predict their binding affinities on SARS-CoV-2 main protease (PDB ID: 6LU7), spike glycoprotein (PDB ID: 6LZG), and human ACE2 (PDB ID: 1R42). The obtained results are summarized in Supplementary Table 1.

3.2. Toxicity Risks and Drug Likeliness. Twenty-seven compounds are predicted to have no risk of mutagenic, tumorigenic, irritant, or reproductive effects and have drug score $>0.5$ as shown in Table 1 . These were selected for subsequent steps. 
TAble 1: Toxicity risks and drug likeliness predicted by OSIRIS Property Explorer.

\begin{tabular}{|c|c|c|c|c|c|c|c|}
\hline No. & Compound name & $\mathrm{ME}$ & TE & $\mathrm{IE}$ & $\mathrm{RE}$ & DL & DS \\
\hline 1 & Uranidine & - & - & - & - & 0.50 & 0.78 \\
\hline 2 & 1-Methyl-2-[6'-( $3^{\prime \prime}, 4^{\prime \prime}$-methylenedioxyphenyl)hexyl]-4-quinolone & - & - & - & - & -0.86 & 0.55 \\
\hline 3 & 4-Methoxy-1-methylquinolin-2-one & - & - & - & - & 1.90 & 0.89 \\
\hline 4 & 2-Acetyl-4(3H)-quinazolinone & - & - & - & - & 3.11 & 0.94 \\
\hline 5 & Chimanine D & - & - & - & - & -0.28 & 0.66 \\
\hline 6 & Cuspareine & - & - & - & - & 4.79 & 0.69 \\
\hline 7 & Galipeine & - & - & - & - & 3.54 & 0.79 \\
\hline 8 & Galipinine & - & - & - & - & 2.45 & 0.59 \\
\hline 9 & Acronydine & - & - & - & - & 2.76 & 0.86 \\
\hline 10 & Veprisine & - & - & - & - & 2.76 & 0.86 \\
\hline 11 & Isofebrifugine & - & - & - & - & 4.19 & 0.91 \\
\hline 12 & 2-Methoxyrutaecarpine & - & - & - & - & 5.25 & 0.8 \\
\hline 13 & 2-Methoxy-13-methylrutaecarpine & - & - & - & - & 6.09 & 0.81 \\
\hline 14 & Tryptanthrin & - & - & - & - & 3.28 & 0.84 \\
\hline 15 & Neosartoryadin A & - & - & - & - & 3.32 & 0.71 \\
\hline 16 & Neosartoryadin B & - & - & - & - & 1.15 & 0.63 \\
\hline 17 & Oxoglyantrypine & - & - & - & - & 4.00 & 0.87 \\
\hline 18 & Norquinadoline A & - & - & - & - & 7.04 & 0.74 \\
\hline 19 & Deoxynortryptoquivaline & - & - & - & - & 4.44 & 0.66 \\
\hline 20 & Quinadoline A & - & - & - & - & 7.19 & 0.72 \\
\hline 21 & 3-Hydroglyantrypine & - & - & - & - & 4.2 & 0.89 \\
\hline 22 & Cladoquinazoline & - & - & - & - & 3.91 & 0.82 \\
\hline 23 & Epi-cladoquinazoline & - & - & - & - & 3.91 & 0.82 \\
\hline 24 & Glyantrypine & - & - & - & - & 3.84 & 0.89 \\
\hline 25 & Deoxytrytoquivaline & - & - & - & - & 5.93 & 0.58 \\
\hline 26 & Prelapatine B & - & - & - & - & 3.72 & 0.88 \\
\hline 27 & Waltherione A & - & - & - & - & -0.01 & 0.54 \\
\hline
\end{tabular}

ME: mutagenic effect; TE: tumorigenic effect; IE: irritant effect; RE: reproductive effect; DL: drug likeliness; DS: drug score; (-): no risk.

3.3. Physicochemical Parameters. The physicochemical properties of the selected twenty-seven compounds were predicted by the SwissADME web tool. Ten compounds were found to be soluble, and seventeen were predicted to be moderately soluble as shown in Table 2. The physicochemical properties influence the pharmacokinetic properties which in turn determines the ultimate biological effect.

3.4. In Silico ADME Properties. The selected compounds were subjected to pharmacokinetic analysis using the SwissADME tool. The obtained results are summarized in Table 3.

3.5. Analysis and Visualization. Molecular docking using AutoDock 4.0 was conducted for most promising compounds with DS values $\geq 0.5$, no risk of toxicity, and considerable solubility (Figure 1 and Table 4 ).

Visualization was then performed for five compounds, against each target, showing the best docking score (lowest binding energies). Figures 2-4 show the intermolecular interaction and hydrogen bonding between the ligands and proteins at the active sites. Important active site residues in each of the three targets are involved in ligands' binding (Table 5).

\section{Discussion}

SARS-CoV-2 is an RNA virus which tends to mutate more commonly than the DNA viruses. It has killed thousands of people around the globe with an increase in death rate every single day. In order to control and treat such pandemics, drug repurposing is highly recommended as it involves the use of derisked compounds with potentially lower development cost and shorter timelines. Moreover, discovery of multitarget drugs can be accelerated by in silico screening of potential ligands on a number of promising drug targets. In our present study, natural quinoline and quinazoline alkaloids were screened in silico against three macromolecules selected as potential therapeutic targets for treatment of COVID-19 infection.

4.1. Compounds' Screening. The obtained results (Supplementary Table 1) revealed that most of the compounds have good affinity with binding energies ranging from -5.0 to $-10.8 \mathrm{kcal} / \mathrm{mol}$. Therefore, in order to select the most promising and potential candidates, evaluation of toxicity risks and drug likeliness was performed.

4.2. In Silico ADME Properties. Results predicted that twenty-three compounds have promise being drugs or drug leads since they showed no risk of mutagenic, tumorigenic, 
TABLE 2: Physicochemical properties of selected compounds.

\begin{tabular}{|c|c|c|c|c|c|c|c|}
\hline Compound no. & $\mathrm{MW}(\mathrm{g} / \mathrm{mol})$ & NRBs & NHBAs & NHBDs & $\operatorname{TPSA}\left(\mathrm{A}^{\circ} 2\right)$ & Consensus $\log \mathrm{Po} / \mathrm{w}$ & Water solubility class \\
\hline 1 & 193.16 & 0 & 4 & 4 & 93.55 & 0.66 & Soluble \\
\hline 2 & 259.3 & 2 & 4 & 1 & 51.58 & 2.44 & Soluble \\
\hline 3 & 189.21 & 1 & 2 & 0 & 31.23 & 1.73 & Soluble \\
\hline 4 & 188.18 & 1 & 3 & 1 & 62.82 & 1.2 & Soluble \\
\hline 5 & 185.22 & 1 & 2 & 0 & 25.42 & 2.39 & Soluble \\
\hline 6 & 311.42 & 5 & 2 & 0 & 21.7 & 3.93 & Moderately soluble \\
\hline 7 & 283.36 & 3 & 2 & 1 & 32.7 & 3.29 & Moderately soluble \\
\hline 8 & 295.38 & 3 & 2 & 0 & 21.7 & 3.83 & Moderately soluble \\
\hline 9 & 301.34 & 2 & 4 & 0 & 49.69 & 2.61 & Soluble \\
\hline 10 & 301.34 & 2 & 4 & 0 & 49.69 & 2.61 & Soluble \\
\hline 11 & 301.34 & 2 & 5 & 2 & 76.38 & 1.04 & Soluble \\
\hline 12 & 317.34 & 1 & 3 & 1 & 59.91 & 3.09 & Moderately soluble \\
\hline 13 & 331.37 & 1 & 3 & 0 & 49.05 & 3.02 & Moderately soluble \\
\hline 14 & 248.24 & 0 & 3 & 0 & 51.96 & 2.16 & Soluble \\
\hline 15 & 472.49 & 0 & 7 & 2 & 118.7 & 1.58 & Moderately soluble \\
\hline 16 & 488.49 & 0 & 8 & 2 & 130.14 & 1.25 & Moderately soluble \\
\hline 17 & 358.35 & 2 & 4 & 2 & 101.79 & 1.9 & Moderately soluble \\
\hline 18 & 471.51 & 2 & 6 & 3 & 121.5 & 1.6 & Moderately soluble \\
\hline 19 & 516.55 & 5 & 8 & 1 & 124.77 & 2.45 & Moderately soluble \\
\hline 20 & 485.53 & 2 & 6 & 3 & 121.5 & 1.82 & Moderately soluble \\
\hline 21 & 360.37 & 2 & 4 & 3 & 104.95 & 1.51 & Soluble \\
\hline 22 & 418.45 & 3 & 5 & 3 & 118.26 & 1.47 & Moderately soluble \\
\hline 23 & 418.45 & 3 & 5 & 3 & 118.26 & 1.47 & Moderately soluble \\
\hline 24 & 344.37 & 2 & 3 & 2 & 84.72 & 2.04 & Moderately soluble \\
\hline 25 & 516.59 & 5 & 7 & 1 & 100.54 & 2.93 & Moderately soluble \\
\hline 26 & 342.35 & 0 & 3 & 2 & 84.72 & 1.79 & Moderately soluble \\
\hline 27 & 393.43 & 3 & 5 & 2 & 85.12 & 2.96 & Moderately soluble \\
\hline
\end{tabular}

LogPo/w: partition coefficient; NHBDs: number of hydrogen bond donors; NHBAs: number of hydrogen bond acceptors; NRBs: number of rotatable bonds; TPSA: topological surface area.

TABle 3: Predicted ADME properties of selected compounds.

\begin{tabular}{|c|c|c|c|c|c|c|c|c|c|}
\hline $\begin{array}{l}\text { Molecule } \\
\text { no. }\end{array}$ & HIA & $\begin{array}{c}\mathrm{BBB} \\
\text { permeant }\end{array}$ & $\begin{array}{c}\text { P-gp } \\
\text { substrate }\end{array}$ & $\begin{array}{l}\text { CYP1A2 } \\
\text { inhibitor }\end{array}$ & $\begin{array}{l}\text { CYP2C19 } \\
\text { inhibitor }\end{array}$ & $\begin{array}{l}\text { CYP2C9 } \\
\text { inhibitor }\end{array}$ & $\begin{array}{l}\text { CYP2D6 } \\
\text { inhibitor }\end{array}$ & $\begin{array}{l}\text { CYP3A4 } \\
\text { inhibitor }\end{array}$ & $\begin{array}{c}\log \mathrm{Kp} \\
(\mathrm{cm} / \mathrm{s})\end{array}$ \\
\hline 1 & High & No & No & No & Yes & No & No & Yes & -6.59 \\
\hline 6 & High & Yes & Yes & Yes & No & No & Yes & No & -6.11 \\
\hline 7 & High & Yes & No & Yes & No & No & No & No & -6.6 \\
\hline 8 & High & Yes & No & Yes & No & No & No & No & -6.7 \\
\hline 12 & High & Yes & No & No & No & No & No & No & -5.92 \\
\hline 20 & High & Yes & No & Yes & No & Yes & Yes & Yes & -4.82 \\
\hline 21 & High & Yes & No & Yes & No & No & Yes & No & -5.14 \\
\hline 22 & High & Yes & Yes & Yes & No & Yes & Yes & Yes & -4.81 \\
\hline 28 & High & Yes & No & Yes & Yes & Yes & Yes & No & -6.64 \\
\hline 29 & High & Yes & No & Yes & Yes & Yes & Yes & No & -6.64 \\
\hline 33 & High & No & Yes & No & No & No & Yes & No & -7.88 \\
\hline 34 & High & Yes & Yes & Yes & No & Yes & Yes & Yes & -6.11 \\
\hline 35 & High & Yes & Yes & Yes & No & Yes & No & Yes & -6.23 \\
\hline 36 & High & Yes & No & Yes & No & No & No & No & -6.36 \\
\hline 54 & High & No & No & No & No & No & Yes & No & -7.83 \\
\hline 55 & High & No & No & No & No & No & No & No & -7.95 \\
\hline 56 & High & No & Yes & No & Yes & No & No & No & -6.31 \\
\hline 57 & High & No & Yes & No & No & No & No & No & -7.53 \\
\hline 58 & High & No & No & No & No & No & Yes & Yes & -7.07 \\
\hline 60 & High & No & Yes & No & No & No & No & No & -7.48 \\
\hline 61 & High & No & No & No & Yes & No & No & No & -6.89 \\
\hline 62 & High & No & Yes & No & No & No & No & Yes & -7.23 \\
\hline 63 & High & No & Yes & No & No & No & No & Yes & -7.23 \\
\hline 64 & High & No & Yes & Yes & Yes & No & Yes & No & -6.4 \\
\hline 65 & High & No & Yes & No & No & No & Yes & Yes & -7.38 \\
\hline 66 & High & No & Yes & Yes & Yes & No & No & No & -6.52 \\
\hline 69 & High & No & Yes & No & No & No & Yes & Yes & -6.7 \\
\hline
\end{tabular}

HIA: human gastrointestinal absorption; BBB permeant: blood-brain barrier permeability; P-gp substrate: permeability glycoprotein substrate; Kp: skin permeability coefficient. 


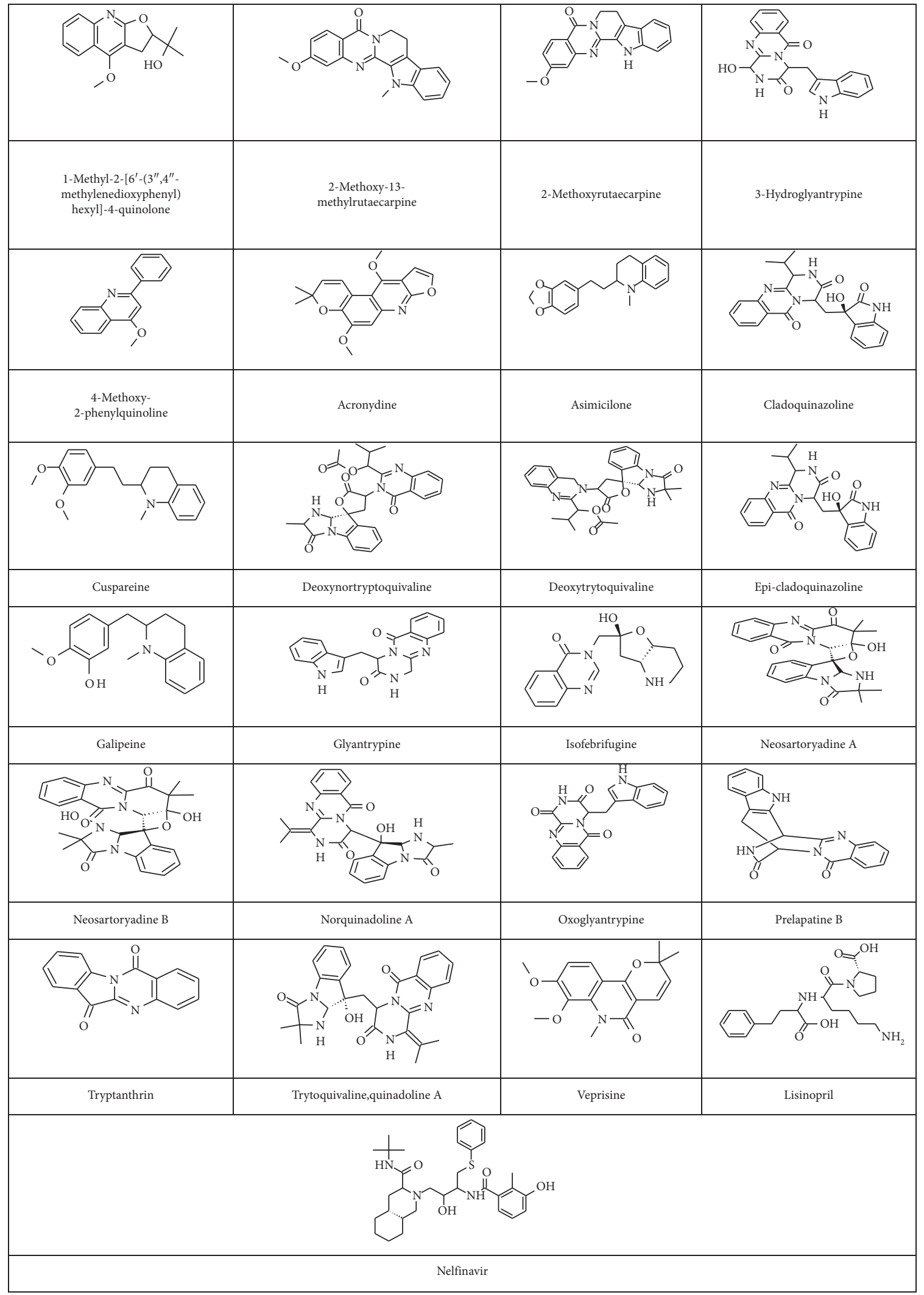

FIgURE 1: Chemical structures of selected ligands for molecular docking. 
TABLE 4: Molecular docking results of promising compounds against the three targets.

\begin{tabular}{|c|c|c|c|}
\hline Compound name & $\begin{array}{l}\text { Min. binding energy on main } \\
\text { protease (6LU7; kcal/mol) }\end{array}$ & $\begin{array}{c}\text { Min. binding energy on } \\
\text { human ACE2 (IR42; kcal/ } \\
\text { mol) }\end{array}$ & $\begin{array}{l}\text { Min. binding energy on spike } \\
\text { glycoprotein ( } 6 \mathrm{LZG} ; \mathrm{kcal} / \mathrm{mol})\end{array}$ \\
\hline $\begin{array}{l}\text { 1-Methyl-2-[6'-( } 3^{\prime \prime}, 4^{\prime \prime}- \\
\text { methylenedioxyphenyl)hexyl]-4- } \\
\text { quinolone }\end{array}$ & -8.11 & -6.25 & -7.40 \\
\hline 4-Methoxy-2-phenylquinoline & -6.50 & -6.73 & 7.26 \\
\hline Cuspareine & -6.59 & -6.62 & -5.86 \\
\hline Galipeine & -6.73 & -6.34 & -7.12 \\
\hline Asimicilone & -7.25 & -6.72 & -7.2 \\
\hline Acronydine & -7.20 & -6.31 & -6.26 \\
\hline Veprisine & -7.25 & -6.30 & -6.81 \\
\hline Isofebrifugine & -7.10 & -8.35 & -7.16 \\
\hline 2-Methoxyrutaecarpine & -7.35 & -7.31 & -8.70 \\
\hline 2-Methoxy-13-methylrutaecarpine & -7.11 & -7.37 & -7.58 \\
\hline Tryptanthrin & -6.95 & -6.35 & -6.68 \\
\hline Neosartoryadin A & -8.34 & -9.08 & -8.6 \\
\hline Neosartoryadin B & -7.49 & -8.09 & -8.1 \\
\hline Oxoglyantrypine & -8.76 & -8.26 & -7.5 \\
\hline Norquinadoline A & -8.75 & -10.63 & -8.98 \\
\hline Deoxynortryptoquivaline & -9.64 & -10.24 & -9.53 \\
\hline Trytoquivaline, quinadoline A & -8.61 & -11.01 & -8.95 \\
\hline 3-Hydroglyantrypine & -9.19 & -8.13 & -7.6 \\
\hline Cladoquinazoline & -7.77 & -8.24 & -7.4 \\
\hline Epi-cladoquinazoline & -8.08 & -8.84 & -7.2 \\
\hline Glyantrypine & -8.60 & -8.02 & -7.7 \\
\hline Deoxytrytoquivaline & -9.34 & -10.05 & -9.22 \\
\hline Prelapatine B & -7.91 & -8.38 & -8.5 \\
\hline
\end{tabular}

reproductive, or irritant effects, with drug scores (DS) $>0.5$. Their physicochemical properties indicated that they are less likely to have solubility problems which could lead to poor bioavailability as well as formulation problems [46]. Indeed, this acceptable profile of solubility has been translated in the ADME profile as solubility can also influence it. All the selected compounds were predicted to be highly absorbed from the gastrointestinal tract. Twelve compounds were predicted to permeate the $\mathrm{BBB}$, of which four were also potential substrates for P-gp which could pump them out of the central nervous system (CNS) preventing any serious effects.

Many drugs are metabolized by cytochrome P450 (CYP) enzymes [47]; therefore, assessment of the effect of potential drug candidates on these enzymes is essential. Most of the selected compounds were predicted to inhibit one or two of the five CYP enzymes tested in this study. However, cuspareine, galipinine, acronydine, veprisine, 2-methoxyrutaecarpine, and 2-methoxy-13-methylrutaecarpine were predicted to inhibit four CYP enzymes indicating possible adverse effects and drug-drug interactions [48, 49].

4.3. Molecular Docking Analysis and Visualization. The most potential 23 compounds with DS score $\geq 0.5$ and no risk of toxicity were redocked against the three targets using AutoDock 4.0. Table 4 shows their different binding energies with 6LU7 (ranging between -6.5 and $-9.64 \mathrm{kcal} / \mathrm{mol}$ ), IR42 (ranging between -6.2 and $-11.01 \mathrm{kcal} / \mathrm{mol}$ ), and $6 \mathrm{LZG}$ (ranging between -5.86 and $-9.53 \mathrm{kcal} / \mathrm{mol}$ ). Compared to nelfinavir, a known protease inhibitor, all docked compounds show lower binding energy to the main protease of SARS-CoV-2 indicating that they have the potential to inhibit viral replication. It is important to note that residues Glu166, His163, His164, Phe140, Cys145, Ser144, and Gln189 are involved in binding of nelfinavir and the selected alkaloids. These residues were recently reported in an inhibitor-bound SARS-CoV-2 protease [50].

The receptor-binding domain of SARS-CoV-2 spike glycoprotein is involved in the virus entry to host cells by binding to ACE2. Our results predicted that the tested alkaloids bind to the receptor-binding domain of SARS-CoV2 spike glycoprotein which could therefore inhibit its binding to its receptor. Notably, important amino acids (Gln493 and Glu484) are responsible for the higher binding of SARS-CoV-2 to human ACE2 compared to SARS-CoV as confirmed by mutagenesis studies. Moreover, they are predicted to bind to human ACE2 in its active site which is not the binding site for virus spike glycoprotein. However, conformational changes in the three-dimensional structure of the protein were reported which affect residues which are important for the binding of the spike protein [51]. In addition, a novel ACE2 inhibitor discovered by molecular docking has also shown effectiveness in blocking SARS-CoV spike protein-mediated cell fusion [9]. Given the high similarity of the SARS-CoV-2 and SARS-CoV binding to the host receptor (ACE2), the same could happen with SARS$\mathrm{CoV}-2$. Eighteen of the alkaloids docked within the active 


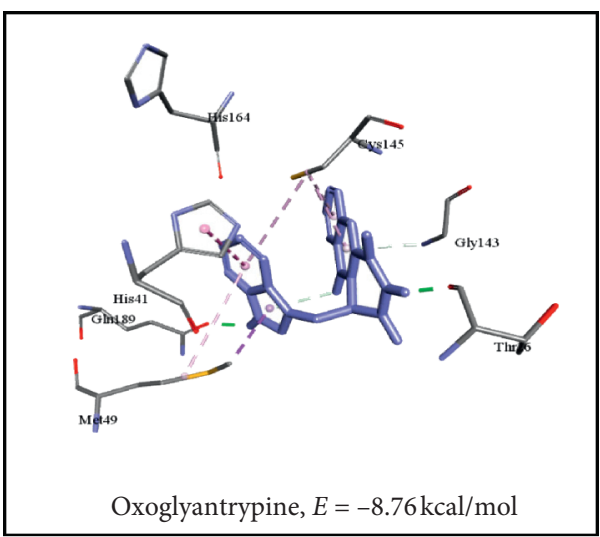

(a)

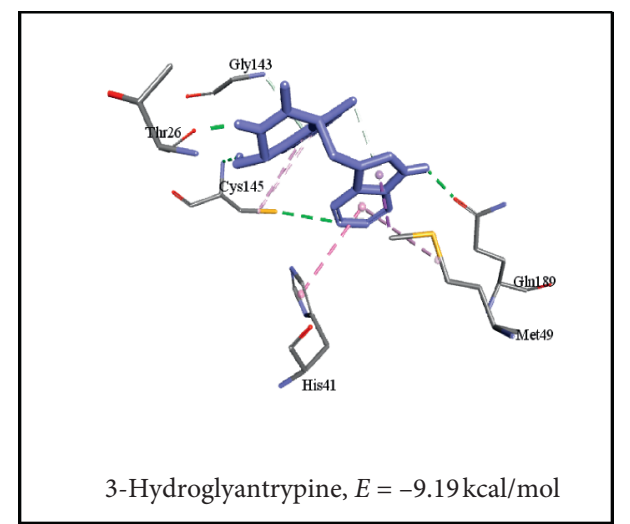

(c)

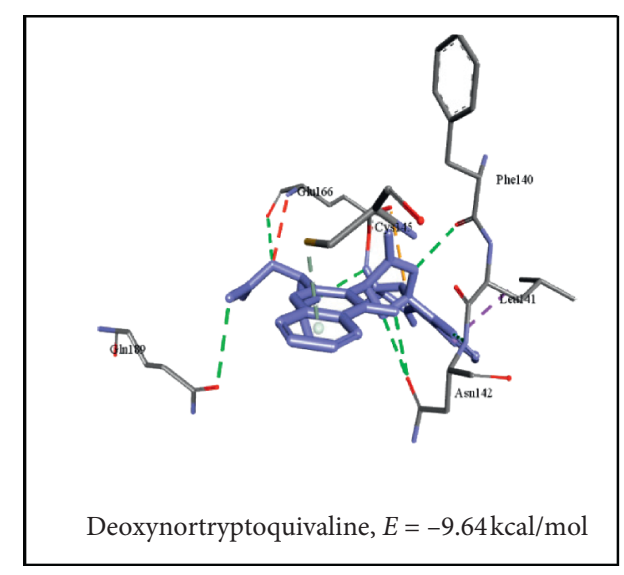

(e)

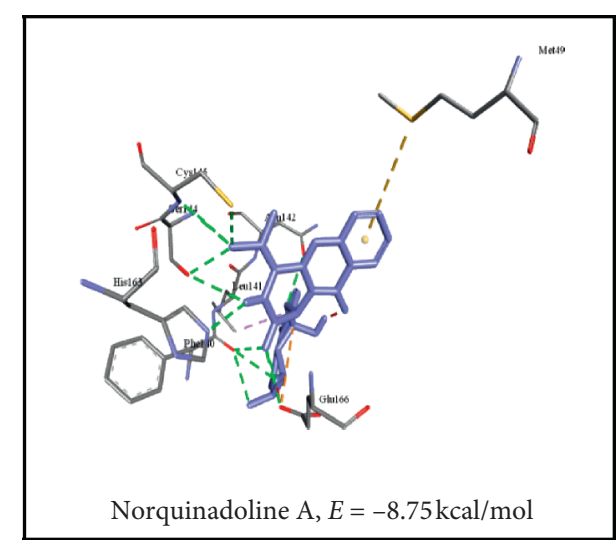

(b)

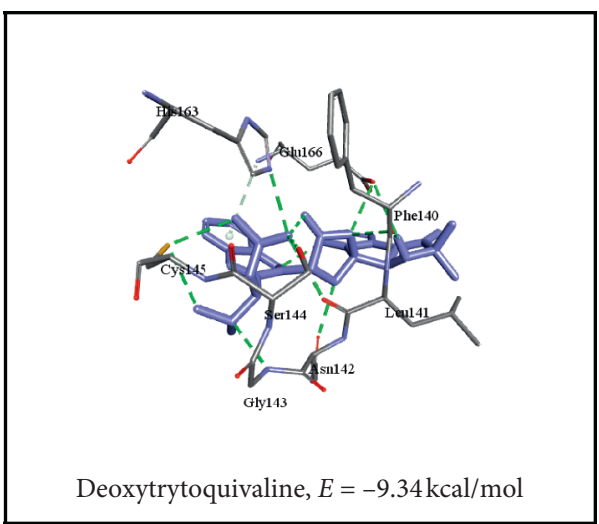

(d)

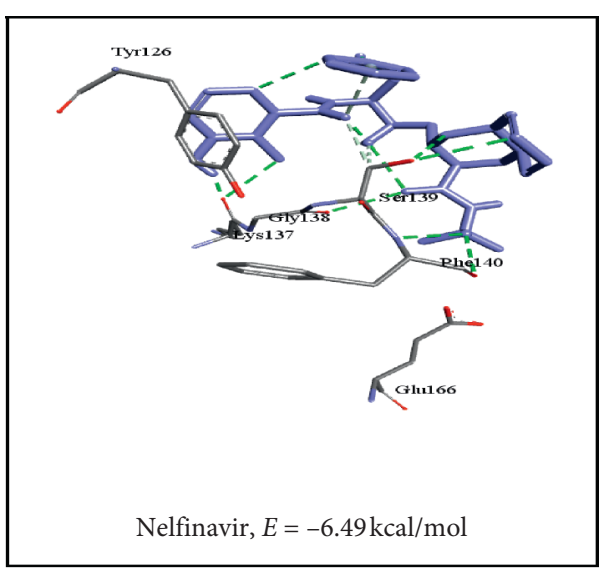

(f)

FIgURE 2: Promising alkaloids in the active site of SARS-CoV-2 main protease (PDB ID: 6LU7). — $\square$ : hydrogen bonding, $\square$ : pi-pi stacked,

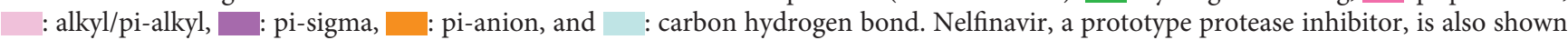
within the active site.

site of human ACE2 exhibit higher binding affinities than lisinopril, which is a prototype the ACE2 inhibitor, with binding energies ranging from 7.31 to $11.01 \mathrm{kcal} / \mathrm{mol}$ compared to $-7.2 \mathrm{kcal} / \mathrm{mol}$ for lisinopril.

Interestingly, three alkaloids, namely, norquinadoline A, deoxytryptoquivaline, and deoxynortryptoquivaline, are predicted to strongly bind the three proteins studied here. These alkaloids are biologically active secondary metabolites isolated from the mangrove-derived fungus Cladosporium sp. PJX-41 and showed anti-influenza A (H1N1) activity [52]. A recent study in which a number of fungal secondary metabolites (including a number of quinoline and quinazoline alkaloids) were virtually screened against five targets of SARS-CoV-2 has also identified norquinadoline A and deoxynortryptoquivaline as potential inhibitors to main protease [38]. The reported binding energy of 


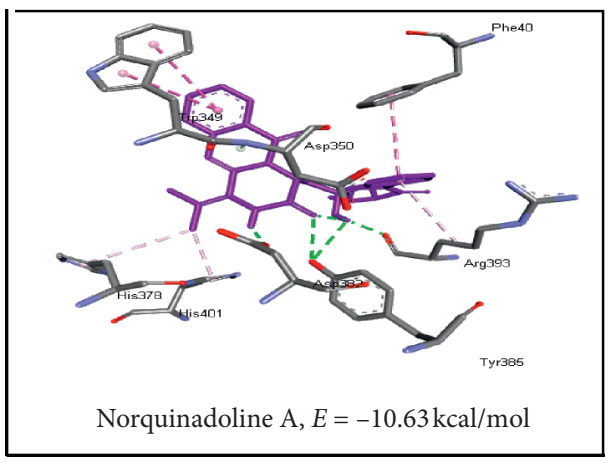

(a)

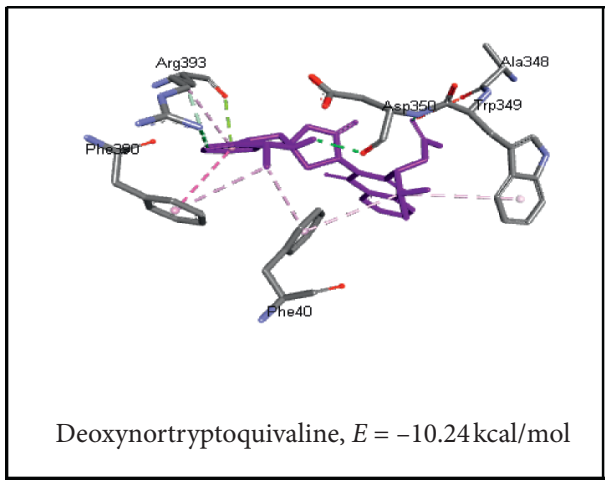

(c)

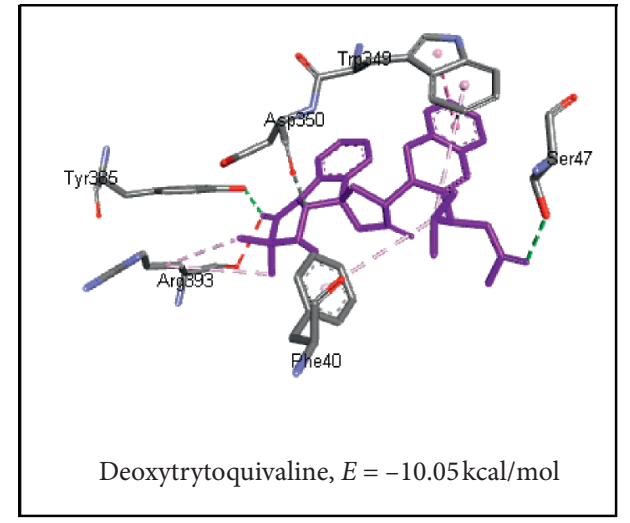

(e)

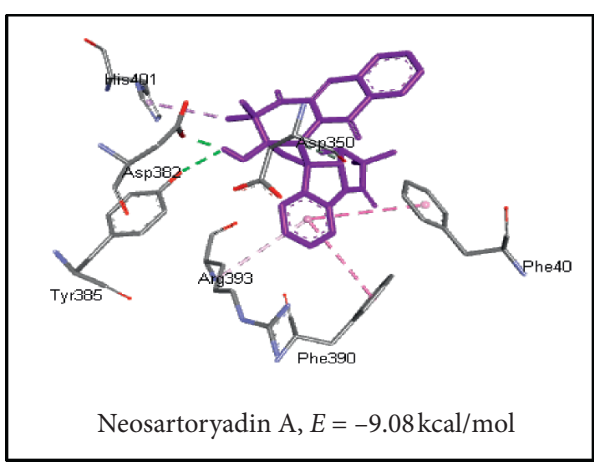

(b)

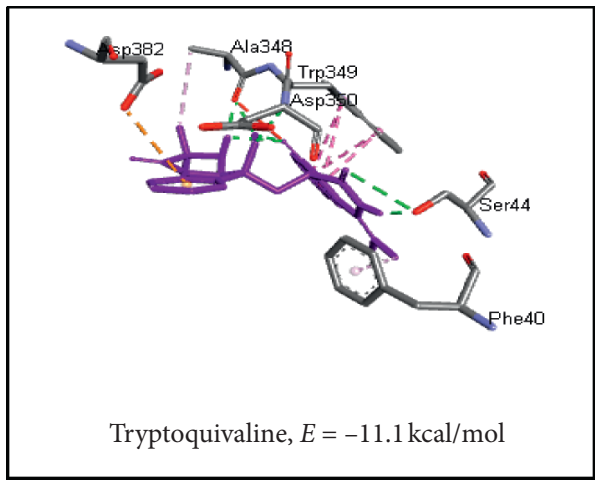

(d)

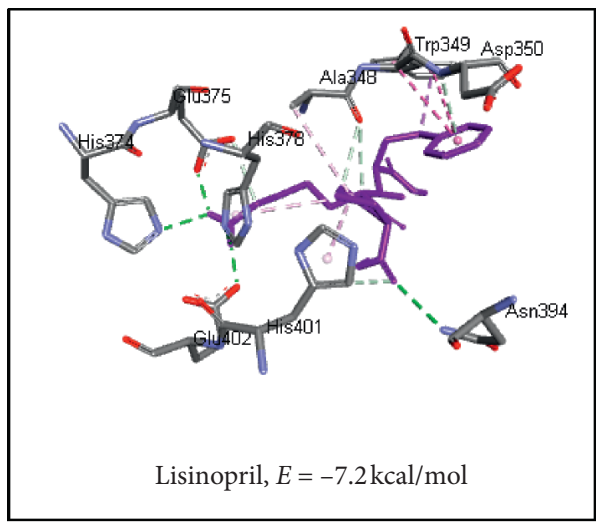

(f)

FIgure 3: Promising alkaloids in the active site of human ACE2 (PDB ID: 1R42). $\square$ : hydrogen bonding, —: pi-pi stacked, $\square$ : alkyl/pialkyl, $\_$: pi-sigma, $\square$ : pi-anion, and $\quad$ : carbon hydrogen bond. Lisinopril, a prototype ACEI, is also shown within the active site.

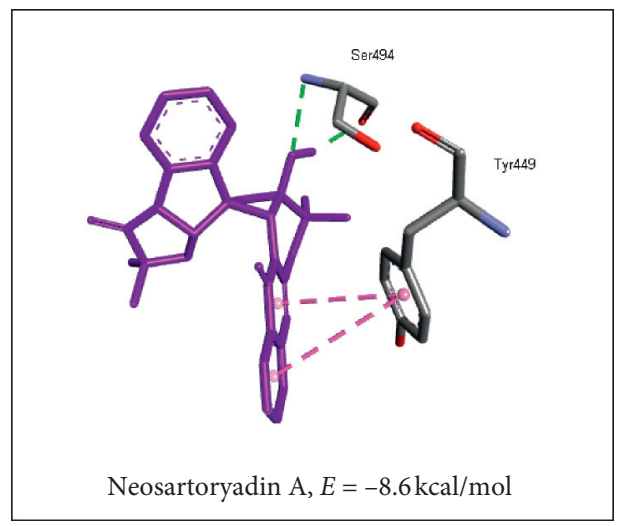

(a)

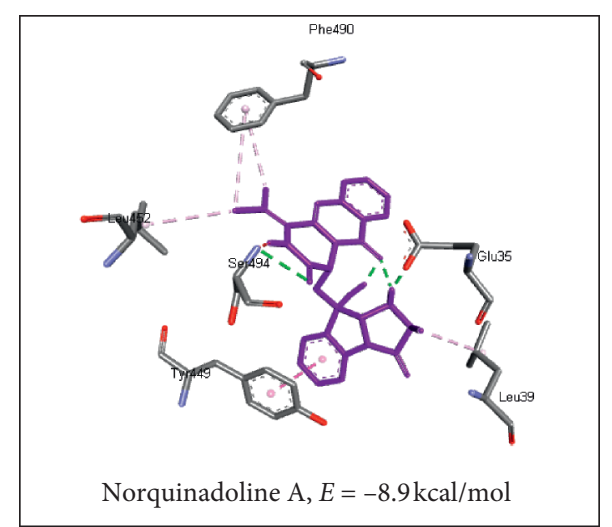

(b)

Figure 4: Continued. 


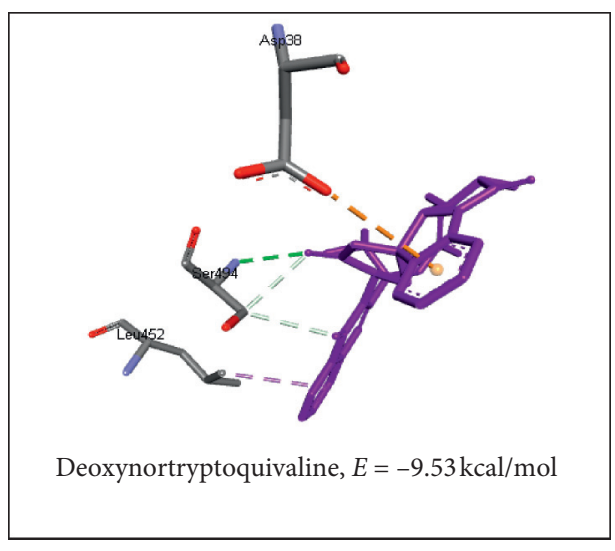

(c)

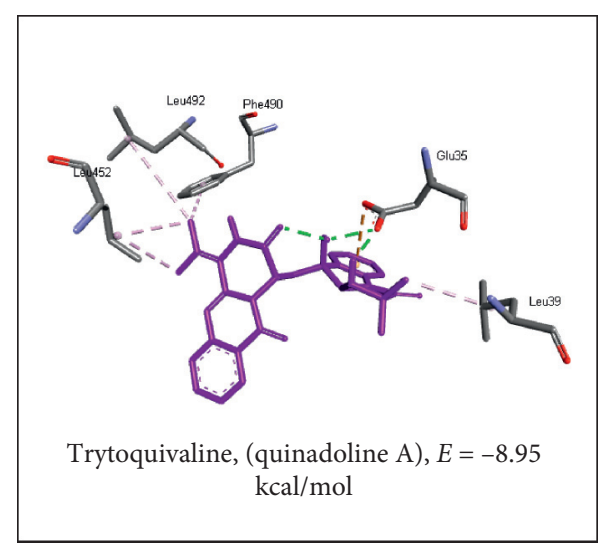

(d)

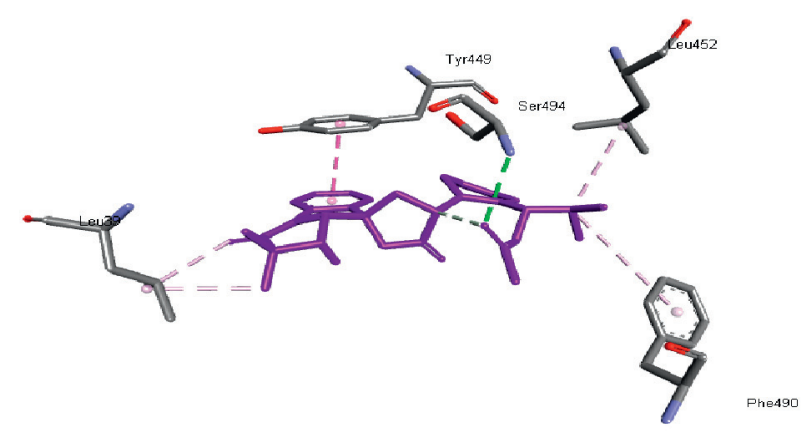

Deoxytrytoquivaline, $E=-9.22 \mathrm{kcal} / \mathrm{mol}$

(e)

FIGURe 4: Promising alkaloids bound to the SARS-CoV-2 spike glycoprotein binding domain (PDB ID: 6LZG). —: hydrogen bonding, pi-pi stacked, $\square$ : alkyl/pi-alkyl, $\square$ : pi-sigma, $\square$ : pi-anion, and $\quad$ : carbon hydrogen bond.

TABLE 5: Amino acid residues involved in the binding of promising alkaloids on the three targets.

\begin{tabular}{lc}
\hline Target name, PDB ID & Amino acids involved in binding interactions \\
\hline $\begin{array}{l}\text { SARS-CoV-2 main protease, 6LU7 } \\
\text { SARS-CoV-2 spike receptor-binding domain, 6LZG }\end{array}$ & $\begin{array}{c}\text { Ser1, Thr24, Thr26, Met49, Phe140, Asn142, Gly143, Ser144, Cys145, His163, } \\
\text { His164, Glu166, Pro168, His172, Gln189 }\end{array}$ \\
$\begin{array}{l}\text { Human angiotensin-converting enzyme-related } \\
\text { carboxypeptidase (ACE2), 1R42 }\end{array}$ & Asn394, Asp382, Tyr385, Arg393, Asp350, Leu351, Gly352, Trp349, His401, \\
His378, Ala348
\end{tabular}

norquinadoline A $(-8.1 \mathrm{kcal} / \mathrm{mol})$ is comparable to our result here $(-8.75 \mathrm{kcal} / \mathrm{mol})$. Both alkaloids showed stronger binding to the papain-like protease of the virus.

Many late-stage failures in drug discovery occur as a result of poor pharmacokinetic and toxicity profiles. Therefore, earlier prediction is essential. The three alkaloids were predicted to have good pharmacokinetic and safety profiles indicating their promise of being taken forward to be tested in vitro and in vivo to prove their effectiveness against SARS-CoV-2.

\section{Conclusion}

Computer-based drug discovery usually involves the search for small-molecule leads with attractive pharmacokinetic and toxicity profiles. These molecules are then tested in vitro and in vivo to confirm their therapeutic potential. Since natural products have played and continue to play a great role in efficacious drug discovery, this study was conducted in order to investigate the potential of selected natural alkaloids against the highly contagious virus SARS-CoV-2 which is responsible for the current pandemic. The study identifies twenty-three alkaloids as possible candidates with the potential to inhibit targets that prevent virus entry and/ or preventing their replication. Of these, norquinadoline A, deoxytryptoquivaline, and deoxynortryptoquivaline inhibit three protein targets and exhibit good pharmacokinetic and safety profiles, suggesting them as possible natural multitarget drugs against COVID-19. Therefore, these three alkaloids could be starting points for future drug development 
efforts, indeed after confirming their effectiveness and mechanisms of action thereafter.

\section{Data Availability}

The data used to support these findings are available within the manuscript and its supplementary file.

\section{Conflicts of Interest}

The authors declare no conflicts of interest.

\section{Authors' Contributions}

Esraa conducted the pharmacokinetic and toxicity analysis. Esraa, Shaza, and Mona performed screening and docking and wrote the paper draft. Wadah and Hassan wrote the introduction. Esraa and Ramzi revised and edited the final draft.

\section{Acknowledgments}

The authors are grateful to the Researchers Supporting Project number (RSP-2020/119), King Saud University, Riyadh, Saudi Arabia, for funding this work.

\section{Supplementary Materials}

Supplementary Table 1: virtual screening results of phytochemicals against SARS-CoV-2 main protease (PDB ID: 6LU7), human angiotensin-converting enzyme 2 (ACE2, PDB ID: IR42), and SARS-CoV-2 spike glycoprotein receptor-binding domain (PDB ID: 6LZG). Supplementary Table 2: toxicity risks and drug likeliness predicted by OSIRIS Property Explorer. (Supplementary Materials)

\section{References}

[1] N. Lo, M. Zhou, X. Dong et al., "Epidemiological and clinical characteristics of 99 cases of 2019 novel coronavirus pneumonia in Wuhan, China: a descriptive study," The Lancet, vol. 395, no. 10223, pp. 507-513, 2020.

[2] N. Zhu, D. Zhang, W. Wang et al., "A novel coronavirus from patients with pneumonia in China, 2019," New England Journal of Medicine, vol. 382, no. 8, pp. 727-733, 2020.

[3] J. F.-W. Chan, S. Yuan, K.-H. Kok et al., "A familial cluster of pneumonia associated with the 2019 novel coronavirus indicating person-to-person transmission: a study of a family cluster," The Lancet, vol. 395, no. 10223, pp. 514-523, 2020.

[4] L. L. Ren, Y. M. Wang, Z. Q. Wu et al., "Identification of a novel coronavirus causing severe pneumonia in human: a descriptive study," Chinese Medical Journal vol. 133, no. 9, pp. 1015-1024, 2020.

[5] N. Yamamoto, R. Yang, Y. Yoshinaka et al., "HIV protease inhibitor nelfinavir inhibits replication of SARS-associated coronavirus," Biochemical and Biophysical Research Communications, vol. 318, no. 3, pp. 719-725, 2004.

[6] Z. Wu and J. M. McGoogan, "Characteristics of and important lessons from the coronavirus disease 2019 (COVID19) outbreak in China," JAMA, vol. 323, no. 13, pp. 1239-1242, 2020.
[7] S. Belouzard, J. K. Millet, B. N. Licitra, and G. R. Whittaker, "Mechanisms of coronavirus cell entry mediated by the viral spike protein,” Viruses, vol. 4, no. 6, pp. 1011-1033, 2012.

[8] F. Li, "Structure, function, and evolution of coronavirus spike proteins," Annual Review of Virology, vol. 3, no. 1, pp. 237-261, 2016.

[9] M. J. Chung, J. Zubcevic, J. A. Hernández Prada et al., "Structure-based discovery of a novel angiotensin-converting enzyme 2 inhibitor," Hypertension, vol. 44, no. 6, pp. 903-906, 2004.

[10] H. Lu, "Drug treatment options for the 2019-new coronavirus (2019-nCoV)," BioScience Trends, vol. 14, no. 1, pp. 69-71, 2020.

[11] Y. Chen, Q. Liu, and D. Guo, "Emerging coronaviruses: genome structure, replication, and pathogenesis," Journal of Medical Virology, vol. 92, no. 4, pp. 418-423, 2020.

[12] A. Maxmen, "More than 80 clinical trials launch to test coronavirus treatments," Nature, vol. 578, no. 7795, pp. 347-348, 2020.

[13] M. T. TahirUlQamar, M. Arooma, I. Muneer et al., "Computational screening of medicinal plant phytochemicals to discover potent pan-serotype inhibitors against dengue virus," Scientific Reports, vol. 9, pp. 1-16, 2019.

[14] J. C. O. Sardi, L. Scorzoni, T. Bernardi, A. M. Fusco-Almeida, and M. J. S. Mendes Giannini, "Candida species: current epidemiology, pathogenicity, biofilm formation, natural antifungal products and new therapeutic options," Journal of Medical Microbiology, vol. 62, no. 1, pp. 10-24, 2013.

[15] U. A. Khan, H. Rahman, Z. Niaz et al., "Antibacterial activity of some medicinal plants against selected human pathogenic bacteria," European Journal of Microbiology and Immunology, vol. 3, no. 4, pp. 272-274, 2013.

[16] R. K. Ganjhu, P. P. Mudgal, H. Maity et al., "Herbal plants and plant preparations as remedial approach for viral diseases," VirusDisease, vol. 26, no. 4, pp. 225-236, 2015.

[17] X.-F. Shang, S. L. Morris-Natschke, Y.-Q. Liu et al., "Biologically active quinoline and quinazoline alkaloids part I," Medicinal Research Reviews, vol. 38, no. 3, pp. 775-828, 2018.

[18] X.-F. Shang, S. L. Morris-Natschke, G.-Z. Yang et al., "Biologically active quinoline and quinazoline alkaloids part II," Medicinal Research Reviews, vol. 38, no. 5, pp. 1614-1660, 2018.

[19] N. Wakui, R. Yoshino, N. Yasuo, M. Ohue, and M. Masakazu, "Exploring the selectivity of inhibitor complexes with Bcl-2 and Bcl-XL: a molecular dynamics simulation approach," Journal of Molecular Graphics and Modelling, vol. 79, pp. 166-174, 2018.

[20] N. Yasuo and M. Sekijima, "Improved method of structurebased virtual screening via interaction-energy-based learning," Journal of Chemical Information and Modeling, vol. 59, no. 3, pp. 1050-1061, 2019.

[21] I. Aanouz, A. Belhassan, K. El-Khatabi, T. Lakhlifi, M. Elldrissi, and M. Bouachrine, "Moroccan Medicinal plants as inhibitors against SARS-CoV-2 main protease: computational investigations," Journal of Biomolecular Structure and Dynamics, vol. 38, pp. 1-9, 2020.

[22] I. Abdelli, F. Hassani, S. Bekkel Brikci, and S. Ghalem, "In silico study the inhibition of Angiotensin converting enzyme 2 receptor of COVID-19 by Ammoides verticillata components harvested from Western Algeria," Journal of Biomolecular Structure and Dynamics, vol. 38, pp. 1-14, 2020.

[23] A. O. Adeoye, B. J. Oso, I. F. Olaoye, H. Tijjani, and A. I. Adebayo, "Repurposing of chloroquine and some clinically approved antiviral drugs as effective therapeutics to 
prevent cellular entry and replication of coronavirus," Journal of Biomolecular Structure and Dynamics, vol. 38, pp. 1-11, 2020.

[24] K. Al-Khafaji, D. AL-Duhaidahawi, and T. Taskin Tok, "Using integrated computational approaches to identify safe and rapid treatment for SARS-CoV-2," Journal of Biomolecular Structure and Dynamics, vol. 38, pp. 1-9, 2020.

[25] A. Basit, T. Ali, and S. U. Rehman, "Truncated human angiotensin converting enzyme 2; a potential inhibitor of SARSCoV-2 spike glycoprotein and potent COVID-19 therapeutic agent," Journal of Biomolecular Structure and Dynamics, vol. 38, pp. 1-10, 2020.

[26] V. K. Bhardwaj, R. Singh, J. Sharma, V. Rajendran, R. Purohit, and S. Kumar, "Identification of bioactive molecules from tea plant as SARS-CoV-2 main protease inhibitors," Journal of Biomolecular Structure and Dynamics, vol. 38, pp. 1-10, 2020.

[27] S. Das, S. Sarmah, S. Lyndem, and A. Singha Roy, "An investigation into the identification of potential inhibitors of SARS-CoV-2 main protease using molecular docking study," Journal of Biomolecular Structure and Dynamics, vol. 38, pp. 1-11, 2020.

[28] A. A. Elfiky, "Anti-HCV, nucleotide inhibitors, repurposing against COVID-19," Life Sciences, vol. 248, Article ID 117477, 2020.

[29] A. A. Elfiky, "Natural products may interfere with SARSCoV-2 attachment to the host cell," Journal of Biomolecular Structure and Dynamics, vol. 38, pp. 1-10, 2020.

[30] A. A. Elfiky, "SARS-CoV-2 RNA dependent RNA polymerase (RdRp) targeting: an in silico perspective," Journal of Biomolecular Structure and Dynamics, vol. 38, pp. 1-9, 2020.

[31] A. D. Elmezayen, A. Al-Obaidi, A. T. Şahin, and K. Yelekçi, "Drug repurposing for coronavirus (COVID-19): in silico screening of known drugs against coronavirus 3CL hydrolase and protease enzymes," Journal of Biomolecular Structure and Dynamics, vol. 38, pp. 1-13, 2020.

[32] S. K. Enmozhi, K. Raja, I. Sebastine, and J. Joseph, "Andrographolide as a potential inhibitor of SARS-CoV-2 main protease: an in silico approach," Journal of Biomolecular Structure and Dynamics, vol. 38, pp. 1-7, 2020.

[33] R. Islam, M. R. Parves, A. S. Paul et al., “A molecular modeling approach to identify effective antiviral phytochemicals against the main protease of SARS-CoV-2," Journal of Biomolecular Structure and Dynamics, vol. 38, pp. 1-12, 2020.

[34] N. Lobo-Galo, M. Terrazas-López, A. Martínez-Martínez, and Á. G. Díaz-Sánchez, "FDA-approved thiol-reacting drugs that potentially bind into the SARS-CoV-2 main protease, essential for viral replication," Journal of Biomolecular Structure and Dynamics, vol. 38, pp. 1-9, 2020.

[35] P. Sarma, N. Shekhar, M. Prajapat et al., "In-silico homology assisted identification of inhibitor of RNA binding against 2019-nCoV N-protein (N terminal domain)," Journal of Biomolecular Structure and Dynamics, vol. 38, pp. 1-9, 2020.

[36] S. K. Sinha, A. Shakya, S. K. Prasad et al., "An in-silico evaluation of different Saikosaponins for their potency against SARS-CoV-2 using NSP15 and fusion spike glycoprotein as targets," Journal of Biomolecular Structure and Dynamics, vol. 38, pp. 1-12, 2020.

[37] R. S. Joshi, S. S. Jagdale, S. B. Bansode et al., "Discovery of potential multi-target-directed ligands by targeting hostspecific SARS-CoV-2 structurally conserved main protease," Journal of Biomolecular Structure and Dynamics, vol. 38, pp. 1-16, 2020.

[38] M. T. J. Quimque, K. I. R. Notarte, R. A. T. Fernandez et al., "Virtual screening-driven drug discovery of SARS-CoV2 enzyme inhibitors targeting viral attachment, replication, post-translational modification and host immunity evasion infection mechanisms," Journal of Biomolecular Structure and Dynamics, pp. 1-18, 2020.

[39] N. Guex and M. C. Peitsch, "SWISS-MODEL and the swissPdb viewer: an environment for comparative protein modeling," Electrophoresis, vol. 18, no. 15, pp. 2714-2723, 1997.

[40] S. Dallakyan and A. J. Olson, "Small-molecule library screening by docking with PyRx," Methods in Molecular Biology, vol. 1263, pp. 243-250, 2015.

[41] N. S. Pagadala, K. Syed, and J. Tuszynski, "Software for molecular docking: a review," Biophysical Reviews, vol. 9, no. 2, pp. 91-102, 2017.

[42] A. Daina, O. Michielin, and V. Zoete, "Swiss ADME: a free web tool to evaluate pharmacokinetics, drug-likeness and medicinal chemistry friendliness of small molecules," Scientific Reports, vol. 7, Article ID 42717, 2017.

[43] Organic Chemistry Portal, 2019, http://www.organicchemistry. org/prog/peo/.

[44] G. M. Morris, D. S. Goodsell, R. S. Halliday et al., "Automated docking using a Lamarckian genetic algorithm and an empirical binding free energy function," Journal of Computational Chemistry, vol. 19, no. 14, pp. 1639-1662, 1998.

[45] G. M. Morris, R. Huey, W. Lindstrom et al., "AutoDock4 and AutoDockTools4: automated docking with selective receptor flexibility," Journal of Computational Chemistry, vol. 30, no. 16 , pp. 2785-2791, 2009.

[46] C. A. S. Bergström, W. N. Charman, and C. J. H. Porter, "Computational prediction of formulation strategies for beyond-rule-of-5 compounds," Advanced Drug Delivery Reviews, vol. 101, pp. 6-21, 2016.

[47] B. Testa and S. D. Kraemer, "The biochemistry of drug metabolism - an introduction-testa-chemistry \& biodiversity," Chemistry \& Biodiversity, vol. 4, no. 3, 2007.

[48] P. F. Hollenberg, "Characteristics and common properties of inhibitors, inducers, and activators of CYP enzymes," Drug Metabolism Reviews, vol. 34, no. 1-2, pp. 17-35, 2002.

[49] S.-M. Huang, J. M. Strong, L. Zhang et al., "New era in drug interaction evaluation: US food and drug administration update on CYP enzymes, transporters, and the guidance process," The Journal of Clinical Pharmacology, vol. 48, no. 6 , pp. 662-670, 2008.

[50] L. Zhang, D. Lin, X. Sun et al., "Crystal structure of SARSCoV-2 main protease provides a basis for design of improved $\alpha$-ketoamide inhibitors," Science, vol. 368, no. 6489, pp. 409-412, 2020.

[51] P. Prabakaran, X. Xiao, and D. S. Dimitrov, "A model of the ACE2 structure and function as a SARS-CoV receptor," Biochemical and Biophysical Research Communications, vol. 314, no. 1, pp. 235-241, 2004.

[52] J. Peng, T. Lin, W. Wang et al., "Antiviral alkaloids produced by the mangrove-derived fungus Cladosporium sp. PJX-41," Journal of Natural Products, vol. 76, no. 6, pp. 1133-1140, 2013. 